\title{
Recensión
}

\section{Fundamentos de la Programación de Educación Física en Primaria}

Zagalaz Sánchez, Ma Luisa. Cachón Zagalaz, Javier. Lara Sánchez, Amador J.

\author{
ISBN: 9788490770559 ISBN Digital: 9788490775943 \\ Publicado 11.11.2014 \\ Páginas 364 \\ Editorial Síntesis. Madrid
}

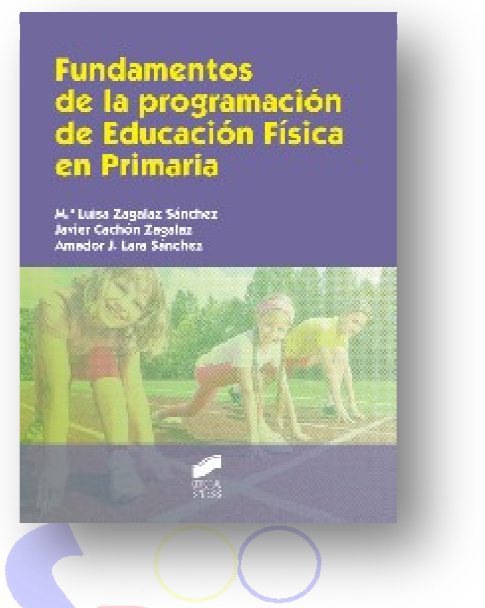

Realizada por: Prof. Dr. Julio Herrador Sánchez

Email: julio_herrador@hotmail.com

El libro Fundamentos de la Programación de Educación Física en Primaria, constituye un manual imprescindible y de lectura obligada tanto para los estudiantes del grado de magisterio en la especialidad de Educación Primaria, como para aquellos titulados que se decidan a preparar y presentarse a las oposiciones. A su vez, puede considerarse como una obra de apoyo académico y profesional para los docentes de dicha especialidad. También puede ser un libro de referencia para los estudiantes de las Facultades de Ciencias de la Actividad Física y el Deporte a la hora de elaborar sus Trabajos Fin de Grado y posteriormente Fin de Máster.

Asimismo, es de una gran utilidad para los doctorandos de los programas relacionados con estos contenidos. En definitiva, la obra permite al lector a reflexionar sobre la importancia de la educación en general y sobre la educación física en particular, así como sobre el rol de su profesorado, ya que lo que se persigue con este manual es permitir conocer el currículum oficial y hacerlo propio, sin copiar ideas de otras personas sino que, en base a ellas, el lector 

sea capaz de establecer sus propios criterios y reflexionar sobre la importancia de la educación y la educación física y del rol de su profesorado.

Se trata de una valiente y completa propuesta de herramientas didácticas, pedagógicas y metodológicas de fácil aplicación en el contexto educativo, con posibilidad de adaptación a los intereses de cada profesional, convirtiéndose en una obra imprescindible para la planificación en la enseñanza.

El libro consta de un interesante prólogo e introducción y está dividido en catorce capítulos:

Antecedentes y concepto de actividad física, La educación física en la etapa de Educación Primaria, El currículo de la educación física en Primaria, Objetivos de la educación física en Primaria, Competencias de la educación física en Primaria, Habilidades motrices y condición física, Actividades artístico-expresivas y actividad física-salud, Juegos y actividades deportivas, Métodos de enseñanza de la educación física en Primaria, Evaluación de la educación física en Primaria, Elementos curriculares complementarios, Planificación y programación de la educación física, Unidades didácticas y sesiones de Educación Física, Innovación e investigación en educación física escolar. Las referencias bibliográficas están muy actualizadas y adaptadas a las nuevas tecnologías (web, link o direcciones electrónicas de interés).

Dichos capítulos, se estructuran en tres Bloques temáticos o partes:

En la primera parte, de acercamiento a la temática general, se explica, desde la perspectiva teórica, lo que es y debe ser la Educación Física -tanto en el contexto de los estudios de Magisterio como en las etapas de Primaria- y los elementos que lo componen. Capítulos fundamentales e imprescindibles en toda obra para centrar el contenido general.

La segunda parte, eminentemente práctica, gira en torno a los aspectos didácticos de la Educación Física. Cualquier diseño curricular consta de una serie de elementos básicos que es preciso conocer, diferenciar y aplicar: objetivos y competencias, contenidos, métodos y procedimientos, y evaluación; conceptos análogos y a la vez diferentes. Cada capítulo está precedido por una presentación de la temática a tratar y a continuación los autores realizan un análisis teórico-práctico pormenorizado y reposado de cada uno de los elementos, y una vez explicado el contenido, proponen ejemplos y actividades de refuerzo. Culmina esta parte con la programación de la Educación Física en Primaria, desde el aspecto general hasta el particular, concretando en lo que es la Unidad Didáctica y las Sesiones propiamente dichas. 
En la tercera parte, se analiza lo que la Educación Física, de una manera indirecta, aporta a la sociedad como un instrumento de desarrollo personal y social, como formación de hábitos saludables, así como la importancia que para ello tienen la innovación e investigación en Educación, transferible al área de Educación Física. En toda ciencia para crecer hay que innovar y para innovar hay que investigar. Todo esto no tendría sentido si el docente no se mentaliza de que es, además de educador, investigador.

Los contenidos específicos se tratan de forma práctica, comenzando con un análisis y reflexión sobre los antecedentes y conceptos básicos para recrearse en las ideas de educación, Educación Primaria, actividad física y Educación Física escolar, dentro de la que se desarrollan los elementos curriculares básicos (objetivos, competencias y contenidos que responden a qué y para qué enseñar; métodos didácticos para saber cómo enseñar y los estándares y resultados de aprendizaje evaluables, más los criterios de evaluación que se corresponden con el concepto más amplio de evaluación y deben contestar a quién o qué, cuándo y cómo evaluar). Completan estos contenidos, los elementos curriculares complementarios como base de las características específicas del contexto y sujetos implicados en el acto educativo, especialmente profesorado.

Sus autores, son docentes de la Universidad de Jaén y nos presentan una obra completa, amena y de fácil lectura, fruto del esfuerzo de personas comprometidas con su profesión y que aporta el conocimiento exhaustivo del currículum oficial actualizado, estableciendo criterios y reflexiones personales sobre la importancia de la educación, la Educación Física y del papel de su profesorado en este contexto. A su vez, pretende dar respuesta a las posibles dudas de cómo se debe llevar a la práctica una planificación docente de la Educación Física, en los cursos de Primaria.

M. ${ }^{a}$ Luisa Zagalaz Sánchez es catedrática en la Universidad de Jaén, donde imparte docencia en el Grado de Primaria y en el Máster en Formación del Profesorado, que también coordina. Además, es coordinadora del Programa de Doctorado en Innovación Didáctica y Formación del Profesorado.

Javier Cachón Zagalaz es profesor en la Universidad de Jaén, donde imparte docencia en los grados de Infantil y Primaria y en el Máster en Formación del Profesorado. 
Cartas al Editor: Recensión de la obra "Fundamentos de la Programación de Educación Física en Primaria"

$\mathrm{N}^{\circ}$ 2(1), pp.106-109. Mayo 2015. A Coruña. España ISSN 2386-8333

Amador J. Lara Sánchez es profesor en la Universidad de Jaén, donde imparte docencia en los grados de Infantil y Primaria, y en el Máster en Investigación y Docencia en Ciencias de la Actividad Física y la Salud.

Julio Herrador Sánchez

Universidad Pablo de Olavide. Sevilla

Referencias Bibliográficas

- Zagalaz, Ma Luisa; Cachón, Javier; Lara, Amador J. (2014). Fundamentos de la

Programacion de Educación Física en Primaria. Madrid: Síntesis. 